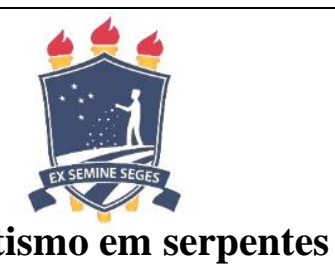

\title{
Parasitismo em serpentes
}

[Parasitism in snakes]

\section{"Revisão/Review"}

\section{Beatriz Brener*, Annelise Amorim Rique, Amanda Leichsenring Diniz, Patricia Riddell Millar}

Departamento de Microbiologia e Parasitologia, Instituto Biomédico, Universidade Federal Fluminense, Niterói-RJ, Brasil.

*Autor para correspondência/Corresponding author: E-mail: beatrizbrener@id.uff.br

\section{Resumo}

A criação cativa de serpentes tem sido cada vez mais intensificada devido ao seu uso como pet, conservação de animais selvagens, importância em pesquisas, desenvolvimento tecnológico, produção de soro antipeçonha e outros produtos. O parasitismo nestes animais é frequente, podendo atingir alta carga parasitária, a qual pode ser intensificada com o estresse de cativeiro que leva à depressão do sistema imunológico. Os parasitos não apenas influenciam na viabilidade dos animais mantidos em cativeiro, como também podem ter potencial zoonótico. Esta revisão visa auxiliar profissionais da área na manutenção adequada de serpentes em cativeiro.

Palavras-chave: ofídios; parasitoses; helmintos; protozoários; ectoparasitos.

\begin{abstract}
The captive breeding of snakes has increased recently due to several reasons: their use as pets, wildlife conservation, research, technological development, antivenom serum production, among others. Parasitism in these animals is common and may reach high rates of parasitic load, intensified due to the stress of captivity, which leads to immune system depression. The parasitic agents not only influence the viability of animals kept in captivity, but also have zoonotic potential. This is a review of Brazilian snakes and their parasites. This review is aimed at assisting professionals in the area of proper captive snake maintenance.
\end{abstract}

Keywords: snakes; parasitosis; helminths; protozoa; ectoparasites.

\section{Introdução}

A perda parcial de um ou mais sistemas metabólicos e da capacidade de utilizar outra fonte nutricional no meio ambiente externo, em todo seu ciclo de vida ou em parte dele, faz com que o parasito se instale em seu hospedeiro e dependa da sobrevida deste (Rey, 2008). O sistema parasito-hospedeiro-meio ambiente é extremamente dinâmico, com variados pontos de estabilidade alcançados durante sua mútua evolução, no entanto, um desequilíbrio desse sistema poderia resultar, a curto ou longo prazo, no desenvolvimento de condições desfavoráveis para um ou ambos os organismos, levando ao surgimento de doenças que podem ser até mesmo fatais (Ferreira, 1973; Rey, 2008).
Poucos são os relatos sobre a importância do parasitismo em répteis, assim como carga parasitária, morbidade ou mortalidade dos mesmos. O conhecimento da fauna parasitária pode ser utilizado para analisar diversos aspectos biológicos de seu hospedeiro, bem como a qualidade ambiental (Jacobson, 2007). Sendo assim, o conhecimento da biodiversidade parasitária pode auxiliar na adequada manutenção destes animais em cativeiro, que ocorre devido à necessidade de conservação de animais selvagens, criação como pet, importância em pesquisas, desenvolvimento tecnológico, obtenção de peçonha, produção experimental de subprodutos tecnológicos e conhecimento da bioecologia e 
reprodução. Acidentes ofídicos são de alta frequência em países tropicais como o Brasil, o que reforça a importância da criação cativa para produção de soro antipeçonha (Fonteque et al., 2009).

\section{Serpentes}

Serpentes criadas em cativeiro geralmente estão submetidas ao estresse, o que leva à depressão de seu sistema imunológico, acentuando as agressões causadas por parasitos (Greiner e Mader, 2006). A relevância das infecções parasitárias em serpentes aumenta porque a maioria dos animais possui alta carga parasitária e microbiana, adquiridos por transmissão vertical ou horizontal, representando risco tanto para serpentes capturadas quanto para as nascidas em cativeiro (Barbosa et al., 2006).

As informações sobre infecções parasitárias em serpentes ainda são escassas. Muitas espécies de parasitos vêm sendo descritas no mundo. A determinação do ciclo biológico dos parasitos é importante para a compreensão dos mecanismos de agressão e ainda para a realização de um controle efetivo. Dentre os efeitos causados pelas infecções parasitárias em serpentes estão anemia, anorexia, gastroenterite hemorrágica, nefrite, insuficiência hepática e pneumonia (Greiner e Mader, 2006). A gravidade destes sinais influencia diretamente na viabilidade dos ofídios mantidos em cativeiro (Araújo et al., 1999).

As serpentes evoluíram a partir de lagartos que foram perdendo o aparelho locomotor. Seu fóssil mais antigo data de 95 milhões de anos atrás. Contudo, acredita-se que elas possam ter surgido há mais de 140 milhões de anos. Possuem corpo alongado revestido por escamas. Variam de poucos centímetros de comprimento, como as espécies escavadoras, a metros, como grandes constritoras. Os ofídios também possuem diversos padrões de cores, os quais estão relacionados com proteção, ao servir como camuflagem ou advertência; e/ou auxílio na temperatura corporal (Marques et al., 2003; Leão et al., 2014).

Embora costumem apresentar olhos evidentes, os ofídios não enxergam bem. A maioria das espécies é capaz de perceber movimentos, entretanto ainda não se sabe se enxergam cores. A visão tem função importante para as serpentes arborícolas, devido à noção de profundidade necessária para seu deslocamento e orientação. Já em animais de hábito fossorial, os olhos são reduzidos. De modo geral, serpentes que apresentam a pupila redonda possuem hábitos diurnos, enquanto pupilas verticais ou elípticas pertencem a animais de hábitos noturnos (Marques et al., 2003; Bernarde, 2014).

Apresentam audição rudimentar por não possuírem ouvido externo ou tímpano. A percepção de sons se dá por meio da mandíbula associada a outros ossos do crânio que propagam as vibrações sonoras ao ouvido interno (Marques et al., 2003; Bernarde, 2014). Já o olfato é bem desenvolvido, sendo o principal sentido utilizado para explorar o ambiente, possibilitando a localização de presas, predadores e parceiros para acasalamento. A captação de moléculas odoríferas ocorre por meio da exposição da língua, sendo analisadas no órgão vômero-nasal ou órgão de Jacobson, localizado no palato (Marques et al., 2003; Bernarde, 2011; 2014).

Os membros da família Viperidae possuem fosseta loreal, abertura situada ente a narina e o olho, com função termorreceptora. Alguns boídeos possuem as fossetas labiais, localizadas entre as escamas labiais. Estas também são sensíveis às variações de temperatura (Marques et al, 2003; Bernarde, 2014).

As serpentes estão atualmente distribuídas em dez famílias, Aniliidae, Anomalepididae, Boidae, Colubridae, Dipsadidae, Elapidae, Leptotyphlopidae, Tropidophiidae Typhlopidae e Viperidae (Bernarde, 2011; Costa e Bérnils, 2018).

São conhecidas no Brasil 442 espécies de serpentes, (Bernarde, 2011; Costa e Bérnils, 2018) entre não peçonhentas e peçonhentas sem importância em saúde pública, entretanto, o país abriga 30 espécies da família Viperidae e 30 da família Elapidae, ambas peçonhentas. As famílias de maior interesse no Brasil são Boidae, Colubridae, Elapidae e Viperidae (Costa e Bérnils, 2018).

As serpentes desempenham importante papel no equilíbrio populacional, por atuarem como presas e predadoras. São parte fundamental do controle de roedores. São importantes para produção de soro antipeçonha, medicamentos, cola cirúrgica, cicatrizantes e analgésicos, que podem ser 600 vezes mais potentes que a morfina (Barbosa et al., 2006; Bernarde, 2014).

A produção de soro antipeçonha possibilitou a redução de $50 \%$ da letalidade decorrente de acidentes com serpentes peçonhentas. Dessa forma, os estudos focados 
nesses animais têm sido cada vez mais intensificados (Bernarde, 2014).

\section{$\underline{\text { O Parasitismo nas serpentes }}$}

As serpentes podem atuar como hospedeiros definitivos, intermediários e paratênicos de diversos parasitos, que podem contribuir para o desenvolvimento de doenças nesses animais (Klingenberg, 1993; Greiner e Mader, 2006). Sintomas como anorexia ou perda de peso, letargia, deficiência no crescimento e reprodução, vômitos, diarreia, desidratação, depressão, agitação, problemas neurológicos e até morte podem ocorrer (Klingenberg, 1993).

\section{Helmintos}

Nematoides parasitos adultos habitam principalmente órgãos tubulares ou permanecem livres na cavidade celomática. As larvas podem ser encontradas nos pulmões além de outros órgãos devido às migrações (Klingenberg, 1993). Infecções nem sempre geram doença, mas podemse observar lesões no trato gastrointestinal ou demais órgãos por onde a larva tenha passado. Alta carga parasitária pode resultar em perda de nutrientes, destruição tissular, infecções secundárias por bactérias e obstrução (Ramallo, 2005; Bursey e Brooks, 2011).

Os gêneros de ascarídeos encontrados em serpentes são Ophidascaris, Ascaridia, Travassosascaris, Hexametra e Polydelphis. Apenas Ascaridia apresenta ciclo monoxênico, os outros têm roedores e anfíbios como hospedeiros intermediários. Antes de atingirem o seu órgão de eleição, as larvas migram pelo pulmão (Klingenberg, 1993; Freitas, 1968). As serpentes são capazes de tolerar uma carga parasitária média de ascarídeos, que podem causar desnutrição, pois absorvem até $40 \%$ dos nutrientes ingeridos pela serpente (Klingenberg, 1993). Cargas parasitárias elevadas podem ocasionar irritação, hiperemia, hemorragia e obstrução do trato gastrointestinal. A migração larvar pode ocasionar lesões inflamatórias, ulcerativas e purulentas em pulmão, traqueia e outros sítios. Infecções secundárias podem agravar o quadro (Klingenberg, 1993; Araújo et al., 1999).

Pinto et al. (2010) observaram parasitismo pela família Ascarididae em $80 \%$ das Crotalus durissus de vida livre avaliadas, originadas do RJ, SP, MG, TO, PA e PR. Dos animais parasitados, $30 \%$ apresentavam o gênero Hexametra e $20 \%$ o gênero Travassosascaris. O gênero Ophidascaris foi encontrado em $50 \%$ dos animais parasitados, sendo encontradas as espécies $O$. sicki, $O$. durissus, O. arndti. e O. tuberculatum. As espécies $O$. sprenti e $O$. tuberculatum foram relatadas em B. jararaca de vida livre (Siqueira et al., 2005). Silva e colaboradores (2001) em estudo envolvendo Crotalus durissus em sistema semiextensivo encontrou $O$. sprenti no estômago de $16,7 \%$ dos animais.

O gênero Kalicephalus possui ciclo de vida direto com um pequeno número de hospedeiros específicos, contudo há outros potenciais hospedeiros. A infecção pode ocorrer através de água ou alimento contaminados; ou pela penetração ativa da larva na pele da serpente (Klingenberg, 1993). Pode haver a participação de hospedeiros paratênicos, como moluscos e anfíbios. Em cativeiro, altas cargas parasitárias podem se formar em um espaço de tempo relativamente curto. Habitam do esôfago ao reto, fixam-se na mucosa e se alimentam de sangue. Podem ocasionar úlceras hemorrágicas, inflamação severa, anemia, peritonite, infecções secundárias e fezes muco-sanguinolentas (Klingenberg, 1993; Dias et al., 2004).

Pinto et al. (2010) observaram o parasito Kalicephalus costatus no intestino de uma serpente da espécie Crotalus durissus, a qual pertencia a um sistema semi-intensivo de cativeiro no Brasil, assim como Silva et al. (2001). A espécie $K$. inermis foi reportada no estômago de outro exemplar desta serpente, neste caso, de vida livre. Ambas as espécies de parasito foram relatadas por Siqueira et al. (2009) no estômago e intestino, respectivamente, de uma Bothrops jararaca pertencente ao Instituto de Biologia do Exército (IBEx). Os mesmos pesquisadores identificaram o gênero Kalicephalus no intestino de uma B. alternatus.

As fêmeas adultas de Rhabdias spp. e Acanthorhabdias spp. são encontradas no pulmão. São ovovivíparas e os ovos larvados são carreados pelo muco até a cavidade oral, onde podem ser liberados no ambiente ou engolidos pela serpente, levando à liberação nas fezes. No ambiente a larva se desenvolve até terceiro estágio, infectante. Apresentam ciclo de vida direto e infectam o hospedeiro através de penetração percutânea ou ingestão de água e alimentos contaminados (Klingenberg, 1993; Luppi et al., 2007). As infecções são geralmente assintomáticas, apesar da possibilidade de hiperinfecção. A pneumonia pode estar presente, e o animal apresentar a boca 
aberta, ausculta respiratória ruidosa, falta de ar, glote distendida, exsudato mucoso na traqueia, narina e glote, perda de peso e anorexia. Esta sintomatologia é somente observada em animais com infecção bacteriana secundária, decorrente de um alto grau de parasitismo, estresse, higiene inadequada e umidade relativa e temperatura elevadas (Klingenberg, 1993; Luppi et al., 2007). Luppi et al. (2007) observaram a infecção pela espécie Rhabdias labiata em oito serpentes da espécie Boa constrictor amarali da Fundação Zoo-Botânica de Belo Horizonte - MG, sendo todos os animais assintomáticos. Também foi relatada em Bothrops alternatus e Crotalus durissus oriundas do IBEx por Siqueira et al. (2009), e em Crotalus durissus de sistema semi extensivo (Silva et al., 2001).

Strongyloides ophidiae possui ciclo de vida direto e a transmissão ocorre por via percutânea ou oral. Possui fase de vida livre, onde são encontrados machos e fêmeas e forma de vida parasitária, onde observa-se apenas fêmeas partenogênicas no intestino delgado (Veazey et al., 1994). Pode causar enterite com diarreia, decorrente da irritação gastrointestinal, podendo ocasionar fezes com muco. A larva migra para o pulmão levando, ocasionalmente, a sinais clínicos respiratórios. Os relatos incluem nefrite, gastroenterite e ureteres obstruídos e distendidos (Klingenberg, 1993; Veazey et al., 1994;). Há relato de infecção severa com óbito em Python molurus bivitattus nos Estados Unidos (Veazey et al., 1994). No Brasil, o primeiro relato de $S$. ophidiae foi feito por Pereira (1929 apud Santos et al. 2010) em 1929 que observou a fêmea partenogenética na serpente Mastigodryas bifossatus.

Capilarídeos são nematoides delgados parasitos de diversos grupos de animais. Rataj et al. (2011) observaram o parasitismo por Capillaria sp. em alguns exemplares de Python regius criadas em cativeiro oriundas dos Estados Unidos, dado conflitante com Moravec que, em 1986, em uma revisão credita apenas o gênero Paracapillaria parasito de serpentes, com diversas espécies.

Os filarídeos já foram relatados em boídeos, viperídeos e colubrídeos, e possuem ciclo de vida indireto, sendo transmitidos através de artrópodes (Klingenberg, 1993). Geralmente assintomáticas, as infecções são observadas apenas em necropsias. Eventualmente vermes adultos podem obstruir capilares resultando em necrose isquêmica; ou migrar para a pele causando dermatite necrosante ou vesicular (Klingenberg, 1993; Greiner e Mader, 2006). Dracunculus brasiliensis foi descrito em Eunectes murinus (Moravec e Santos, 2009).

Cestoides

Proteocephalidae, Pseudophyllidae e Mesocestoididea são importantes em répteis. A infecção ocorre através da ingestão do hospedeiro intermediário invertebrado ou roedores infectados. O habitat é o intestino delgado. De modo geral não geram doença, mas a intensidade da infecção pode causar desnutrição pela espoliação de nutrientes do hospedeiro; enterite, devido à agressão traumática; e obstrução mecânica. Podem-se formar úlceras na mucosa intestinal, hemorragia e edema. Parasitismo ocasionado por espécies dos gêneros Ophiotaenia e Crepidoboyhrium foram associados à necrose intestinal e a infiltrados linfocitários na túnica muscular do intestino (Klingenberg, 1993; Greiner e Mader, 2006).

Aproximadamente 40 espécies de trematódeos foram reportadas em serpentes desde o início do século XX (Pinto et al., 2012). Trematódeos digenéticos habitam boca, esôfago, pulmão, intestino e rins e seu hospedeiro intermediário mais comum é um caramujo, e raramente ocorre em animais de cativeiro (Klingenberg, 1993). Gêneros importantes parasitos de serpentes são Haplometroides, Ochestosoma, Pneumatophilus, Stomatrema e Zeugorchis. O parasito não costuma ocasionar danos significativos no hospedeiro. Silva et al. (2008) reportaram o parasitismo por Haplometroides intercaecalis em um exemplar de Phalotris matogrossensis pertencente à coleção zoológica da Universidade Federal do Mato Grosso do Sul. Haplometroides buccicola foi descrita pela primeira vez na boca e esôfago de Phalotris lativittatus de São Paulo, Brasil (Silva et al., 2005).

Greiner e Mader (2006) encontraram parasitos do gênero Styphlodora, que acomete o sistema renal, afetando $66 \%$ dos animais estudados, enquanto que Pinto et al. (2012) em um estudo em serpentes de Minas Gerais relataram o parasitismo em sistema renal por Styphlodora gili em um exemplar de Bothrops alternatus, assim como Renifer heterocoelium, Opisthogonimus fariai, Opisthogonimus fonsecai em cavidade oral e esôfago de diversas espécies de serpentes; Ophiodiplostomum spectabile em intestino 
delgado, Travtrema stenocotyle em intestino grosso.

O Filo Acantocephala tem sua importância em ofídios por utilizá-los como hospedeiros paratênicos, principalmente espécies dos gêneros Centrorhynchus e Oligacanthorhynchus (Choi et al., 2010). Contudo há ainda acantocéfalos que possuem serpentes como hospedeiros definitvos, como o Acanthocephalus lutzi, que ocorre no Brasil (Travassos, 1926).

\section{Protozoários}

A infecção por protozoários é muito comum em répteis (Richter et al., 2008a), no entanto, não se sabe ainda a relevância destes para a saúde do animal. Apresentam ciclo de vida direto, e a limpeza e higiene são fundamentais para seu controle. Geralmente vivem em equilíbrio com seu hospedeiro, contudo serpentes mantidas em cativeiro muitas vezes são submetidas à autoinfecção contínua, levando a um aumento da carga parasitária, resultando em manifestações clínicas (Klingenberg, 1993; Richter et al., 2008a).

Muito frequente em répteis, Entamoeba invadens causa infecções sintomáticas ou não. Observada com frequência, sua incidência já foi mais alta, sugerindo uma melhora nos métodos profiláticos adotados (Klingenberg, 1993; Jacobson, 2007). A infecção ocorre por meio da ingestão de água ou alimentos contaminados com cistos (Rey, 2008). Eventualmente o protozoário pode atingir a corrente sanguínea e atingir o fígado, causando necrose, e outros órgãos, tais como rins, pulmão, coração e cérebro (Klingenberg, 1993; Jacobson, 2007; Richter et al., 2008b). Serpentes da espécie Lampropeltis californiae (família Colubridae), popularmente conhecidas como Kingsnakes, costumam ser resistentes à infecção, provavelmente devido à sua dieta composta por outros ofídios. Porém, boídeos, demais colubrídeos, elapídeos e viperídeos são altamente susceptíveis. Podem gerar anorexia, fezes muco-sanguinolentas e tingimento por bile (Klingenberg, 1993). Richter et al. (2008b) observaram a infecção por Entamoeba sp. em um exemplar de Boa constrictor de cativeiro. Donaldson et al. (1975) relataram a morte de seis Boa constrictor, sete Python sp. e sete sucuris Eunectes murinus devido a uma epizootia de E. invadens, em serpentes de cativeiro. Ritcher et al. (2008a) descreveram o gênero em cinco exemplares de Boa sp., uma
Crotalus sp., duas Eunectes sp., uma Python sp., uma Cerastes sp. e uma Coluber sp. Dentre esses animais três Boa sp., uma Crotalus sp., duas Eunectes sp. e uma Python sp. apresentavam E. invadens.

Quanto aos coccídeos, Eimeria spp. e Isospora spp são importantes. A infecção ocorre através da ingestão de água e alimentos contaminados com oocistos esporulados. Animais em cativeiro costumam adoecer devido às condições de higiene precárias ou estresse. Muitos animais apresentam diarreia severa, anorexia, debilidade e ocasionalmente morte (Klingenberg, 1993; Jacobson, 2007). Daszak et al. (2011) observaram o parasitismo por Eimeria mchenryi em um exemplar de Heterodon nasicus.

Dentre os répteis, apenas serpentes, lagartos e tartarugas apresentam criptosporidiose. É mais grave em animais imunossuprimidos. Em serpentes pode ser causada por Cryptosporidium serpensis, $C$. muris e $C$. parvum. (Pedraza-Díaz et al., 2009). É a principal zoonose parasitária de répteis, afetando principalmente criadores. Possui alta morbidade e mortalidade, e muitas vezes é necessária eutanásia do plantel (Cranfield e Graczyk, 1994). Acredita-se que a infecção seja pela ingestão de camundongos infectados, muitas vezes portadores assintomáticos (Klingenberg, 1993; Ruggiero et al., 2011). A doença costuma ser autolimitante em 30 dias e é caracterizada por sintomas gastrointestinais, como diarreia branda por duas a quatro semanas, podendo também ser assintomática. Outros possíveis sintomas são enterite, vômito e regurgitação pós-prandial, prostração, depressão e perda de peso crônica $\mathrm{O}$ animal pode evoluir ao óbito ou permanecer com o agente por meses a anos (Cranfield e Graczyk, 1994). A suspeita clínica ocorre quando há regurgitação crônica acompanhada de falha na resposta à terapia convencional; perda de peso superior a 60-70\%; depressão (geralmente relacionada à dor no trato gastrointestinal) e fezes com muco (Klingenberg, 1993; Ruggiero et al., 2011; Paiva et al., 2013).

Ritcher et al. (2008a) observaram o protozoário em três exemplares de Boa sp., três Elaphe sp. e uma Lampropeltis sp. Ruggiero et al. (2011) realizaram um estudo com oito Boa constrictor amarali, dez Bothrops jararaca e sete Crotalus durissus, em que o diagnóstico foi feito pela Reação em Cadeia da Polimerase(PCR) e observação de oocistos à microscopia de luz, obtidos em sedimento de lavado gástrico. A 
prevalência foi de $44 \%$ e a espécie mais parasitada foi C. durissus $(57,14 \%)$. Apenas três Boa constrictor amarali apresentaram sinais clínicos e vieram a óbito. À necropsia foram observadas lesões compatíveis com criptosporidiose.

Paiva et al. (2013) estudaram oito Bothrops jararaca, duas Epicrates chencria chencria, quatro Pantherophis gutatus, uma Python regius, cinco Eunectes murinus e uma Boa constrictor amarali. Todos os animais apresentaram sinais clínicos, sendo o diagnóstico realizado através de exame de fezes e ELISA (do inglês EnzymeLinked Immunosorbent Assay, ou ensaio de imunoabsorção enzimática) indireto. A perda de peso variou entre 1,8 e $43,4 \%$, sendo que os animais em estado grave tiveram perda significativa da gordura e atrofia da musculatura esquelética. Treze indivíduos vieram a óbito.

Monocercomonadídeos são flagelados encontrados frequentemente nos animais e no homem. Convivem bem com seus hospedeiros, tendo poucos agentes reconhecidos como patogênicos (Borges et al., 2007). A espécie mais comum é Monocercomonas colubrorum, a qual só costuma causar sinais clínicos em casos de alta carga parasitária e/ou sistema imune deficiente do hospedeiro. Sinais clínicos incluem apatia, dor abdominal, agressividade e diarreia, podendo ser observadas enterite e gastrite mucopurulentas (Ritchter et al., 2008a). Embora seu habitat seja o trato gastrointestinal, este parasito já foi relatado na vesícula biliar, pulmão e ovidutos (Zwart et al., 1984; Ritchter et al., 2008a). Ritchter et al. (2008a) realizaram um estudo incluindo 182 serpentes, em que o protozoário mais frequente foi Monocercomonas spp. $(18,68 \%)$, observado em sete Boa sp., quatro Cerastes sp., uma Coluber sp., quarto Crotallus sp., seis Elaphe sp., uma Lachesis sp., uma Morelia sp., seis Python sp. e duas Vipera sp.

Hepatozoon sp. é o protozoário intracelular mais comum em serpentes. Inicialmente eram reconhecidas duas espécies, Hepatozoon romani e Hepatozoon capsulata (Smith, 1996). Este protozoário já foi descrito em diversos viperídeos, como Crotalus durissus terrificus e Caudisona durissa terrifica (O'Dwyer et al., 2003; 2011). Estudos moleculares permitiram identificar novas espécies, em Crotalus durissus terrificus, propostas como Hepatozoon cuestensis sp. nov., Hepatozoon cevapii sp. nov. e Hepatozoon massardii sp. nov. (O'Dwyer et al., 2013).

\section{Ectoparasitos}

Artrópodes ectoparasitos de serpentes podem ser vistos com frequência em criadouros ou centros de pesquisas. Quando presentes em pequeno número causam apenas desconforto e agitação do animal. Contudo, a infestação severa pode causar anemia, lesões na pele com áreas ásperas, predispor a infecções secundárias, inflamação periorbital e edema, prostração, anorexia e morte. Alguns carrapatos, em casos mais raros, podem levar à paralisia e morte.

Os ácaros podem ser responsáveis pela transmissão de patógenos, tais como o Hepatozoon sp., por carrapatos, e Aeromonas hydrophila e outras bactérias gram-negativas, veiculadas pelo ácaro Ophionyssus natricis. (Klingenberg, 1993; Fischer et al., 2009; Faccini e Luz, 2013).

Os ácaros costumam ficar entre as escamas, preferencialmente embaixo da cabeça, na região periocular, labial e nasal, concentrando-se no terço anterior. Raramente são observados na região ventral (Klingenberg, 1993). Dentro do terrário costumam se refugiar nos recantos, substrato, rachaduras da toca ou pote de água, entre outros (Klingenberg, 1993; Barbosa et al., 2006; Fischer et al., 2009). Existem mais de 250 espécies de ácaros parasitos de répteis, sendo o mais comum em serpente a espécie Ophionyssus natricis, e muito frequente o gênero Ophioptes (Mendoza-Roldan, 2017). As condições de temperatura e umidade necessárias para manutenção das serpentes em cativeiro são ótimas para a reprodução do ácaro, fazendo com que se desenvolva abundantemente (Klingenberg, 1993). Os carrapatos observados são dos gêneros Amblyomma, Ornithodoros e Ixobioides (Lizaso, 1982; Pereira et al., 2014).

Amblyomma cajennense infesta animais silvestres, domésticos e o homem. Não é raro que sejam encontrados em animais de sangue frio, contudo, neles estão presentes apenas nos estágios de larva e ninfa. As espécies brasileiras que parasitam serpentes são: A. fuscum, A. rotundatum e A. dissimile. Esta última é a mais comum, parasitando cerca de $60 \%$ dos ofídios (Aragão, 1936; Fischer et al., 2009; Faccini e Luz, 2013). Lizaso (1982) registrou o gênero Amblyomma nas espécies Chironius bicarinatus, Hydrodynatus bincictus, Spilotes pullatus e Waglerophis merremii; muitas vezes associado ao carrapato Ixobioides. Rataj et al. (2011) observaram a infestação em um exemplar de Python regius. 
Brum e Rickes (2003) relataram o parasitismo pela espécie $A$. dissimile em uma serpente Eunectes murinus, até então descrito, em ofídios, somente em Boa constrictor. Posteriormente, a mesma espécie foi reportada em um exemplar de Hydrodynates gigas (Fischer et al., 2009). Viana et al. (2012) fizeram o primeiro registro da espécie A. rotundatum no ofídio Philodryas olfersii. Pereira et al. (2014) identificaram a mesma espécie de Amblyomma e o gênero Ornithodoros em serpentes da subespécie Boa constrictor constrictor e em seus recintos.

Ixobioides sp. foi descrito em Chironius bicarinatus, C. quadricarinatus, Erythrolamprus aesculapii, Leimadophis poecilogyrus, L. typhlus, Liophis meridionalis, Mastigodryas bifossatus, Philodryas olfersii, P. patagoniensis, Simophis rhinostoma, Spilotes pullatus, Thamnodynastes strigatus, Waglerophis merremii e Xenodon neuwiedii, muitas vezes associado a outro ectoparasito (Lizaso, 1982). O autor observou o gênero Ophioptes em Chrironius foveatus, Erythrolamprus aesculapii, Leimadophis poecilogyrus, Liophis meridionalis, Mastigodryas bifossatus, Oxyrhopus trigeminus e Waglerophis merremii. Já o Ophionissus natricis foi observado em uma Boa constrictor (Rataj et al., 2011)

O parasitismo por pulgas em serpentes é raramente observado, visto que não são hospedeiros usuais destes ectoparasitos. De modo geral a aquisição ocorre através de aves e mamíferos infestados que servem de presas às serpentes (Barbosa et al., 2006).

\section{Considerações Finais}

$\mathrm{Na}$ natureza, o equilíbrio parasitohospedeiro-ambiente faz com que os animais estejam parasitados sem, no entanto, manifestar doença. Ao mantermos animais silvestres em cativeiro geralmente ocorre o desenvolvimento de stress pelo confinamento e consequente desequilíbrio desta relação podendo levar ao aparecimento de sinais e sintomas importantes. $\mathrm{O}$ conhecimento dos parasitos, suas relações com os hospedeiros e profilaxia são fundamentais para o manejo adequado e manutenção da saúde de animais em cativeiro.

\section{Conflito de Interesse}

Os autores declaram não existir conflito de interesse.

\section{Referências}

Araújo, T.; Moro, L.; Lúcia, M.; Golloubeef, B.; Vasconcelos, A. Ocorrência de alguns endo e ectoparasitos no serpentário da UNIFENAS Universidade de Alfenas - MG. Brazilian Journal of Veterinary Research and Animal Science, 36(1): 19-22, 1999.

Aragão, H. Ixodias brasileiros e de alguns paizes limitrophes. Memórias do Instituto Oswaldo Cruz, 31: 759-843, 1936.

Barbosa, A.R.; Albuquerque, H.N.; Silva, H.; Ribeiro, I.A.M. Contribuição ao estudo parasitológico de jibóias, Boa constrictor constrictor Linnaeus, 1758, em cativeiro. Revista de Biologia e Ciências da Terra, 6(2): 1-18, 2006.

Bernarde, P.S. Mudanças na classificação de serpentes peçonhentas brasileiras e suas implicações na literatura médica. Gazeta Médica da Bahia, 81(1): 55-63, 2011.

Bernarde, P.S. Serpentes peçonhentas e acidentes ofídicos no Brasil. $1^{\text {a }}$ ed. São Paulo: Anolisbooks, 2014. 224 p.

Borges, F.P.; Gottardi, B.; Stuepp, C.; Larré, A.B.; de Brum Vieira, P.; Tasca, T.; De Carli, G.A. Morphological aspects of Monocercomonas $\mathrm{sp}$. and investigation on probable pseudocysts occurrence. Parasitology Research, 101: 1503-1509, 2007.

Brum, J.; Rickes, E. Amblyomma dissimile Koch, 1844 (Acari: Ixodidae) em serpente sucuri (Eunectes smurinus) (Reptilia: Boidae) no parque zoológico do Rio Grande do Sul. Arquivo do Instituto Biológico, 70(2): 215216, 2003.

Bursey, C.; Brooks, D. Nematode parasites of Costa Rican snakes (Serpentes) with description of a new species of Abbreviata (Physalopteridae).

Comparative Parasitology, 78: 333-358, 2011.

Choi, C.; Lee, H.; Go, J.; Park, Y.; Chai, J.; Seo, M. Extraintestinal migration of Centrorhynchus sp. (Acanthocephala: Centrorhynchidae) in experimentally infected rats. Korean Journal Parasitology, 48(2):139-143, 2010.

Costa, H.C.; Bernils, R.S. Répteis do Brasil e suas Unidades Federativas: Lista de espécies. Herpetologia Brasileira, 7(1): 11-48, 2018.

Cranfield, M.R.; Graczyk, T.K. Experimental infection of elaphid snakes with Cryptosporidium serpentis (Apicomplexa: 
Cryptosporidiidae). Journal of Parasitology, 80: 823-826, 1994.

Daszak, P.; Ball, S.; Streicker, D.; Snow, K. A new species of Eimeria (Apicomplexa: Eimeriidae) from the western Hognose Snake, Heterodon nasicus (Serpentes: Xenodontidae), from Texas. Journal of Parasitology, 97(3): 463-465, 2011.

Dias, R.; Almeida, S.; Prieto, D.; Lima, S. Aspectos ecológicos dos nematóides parasitos de Crotalus durissus terrificus Laurenti, 1768 (Ophidia, Viperidae) em Juiz de Fora, Minas Gerais, Brasil. Revista Brasileira de Zoociências, 6(2): 231-235, 2004.

Donaldson, M. Heyneman, D.; Dempster, R.; Garcia, L. Epizootic of fatal amebiasis among exhibited snakes: epidemiologic, pathologic, and chemotherapeutic considerations. American Journal of Veterinary Research, 36(6): 807-817, 1975.

Faccini, J.; Luz, H. Parasitismo por carrapatos em Anuros no Brasil. Revisão. Veterinária e Zootecnia, 20: 100-111, 2013.

Ferreira, L.F. O Fenômeno Parasitismo. Revista do Instituto de Medicina Tropical de São Paulo, 7(4):261-277, 1973.

Fischer, C.H.B.; Mottin, V.D.; Heerdt, M.; Filadelfo, T.; Ceresér, V.H.; Queirolo, M.T.; Allgayer, M.A. Amblyomma dissimile (Acari: Ixodidae) em Hydrodynastes gigas (Squamata: Colubridae) no estado Mato Grosso do Sul, Brasil - Nota Prévia. Brazilian Journal of Veterinary Research and Animal Science, 46(5): 400-403, 2009.

Fonteque, J.; Kohayagawa, A.; Takahira, R.; Bianchi, E.; Cherubini, A.; Piccinin, A.; Bruder, E.; Ramos, P. Perfil eletroforético das proteínas séricas de serpentes Crotalus durissus terrificus (cascavel) criadas em cativeiro. Pesquisa Veterinária Brasileira, 6(29): 457-460, 2009.

Freitas, J. Revisão do gênero Ophidascaris Baylis, 1921 (Nematoda, Ascaridoidea). Memórias do Instituto Oswaldo Cruz, 66(1): 1-83, 1968.

Greiner, E; Mader, D. Parasitology. In: Mader, D. Reptile medicine and surgery. $2^{\text {nd }}$ ed. Florida: Saunders Elsevier, 2006. 1242 p.

Jacobson, E. Infectious diseases and pathology of reptiles. Florida: Taylor \& Francis Group, 2007. $736 \mathrm{p}$.
Klingenberg, R. Understanding reptile parasites. Special Edition. USA: The Herpetocultural library, 1993. $83 \mathrm{p}$.

Leão, S.M.; Nicolás Pelegrin, N.; Nogueira, C.C.; Brandão, R.A. Natural history of Bothrops itapetiningae Boulenger, 1907 (Serpentes: Viperidae: Crotalinae), an endemic species of the Brazilian Cerrado. Journal of Herpetology: 48(3): 324-331, 2014.

Lizaso, N. Levantamento da fauna acarológica ectoparasita de serpentes não venenosas do Estado de São Paulo. Revista Brasileira de Zoologia, 1(3): 203-209, 1982.

Luppi, M.; Costa, M.; Malta, M.; Tinoco, H.; Motta, R. Tratamento de Rhabdias labiata com levamisol e ivermectina em jiboias (Boa constrictor amarali). Veterinária Notícias, 13(1), 61-65, 2007.

Marques, O.; Eletrovic, A.; Sázima, I. Serpentes da Mata Atlântica. $2^{\mathrm{a}}$ ed. Ribeirão Preto: Holos Editora, 2003. 184 p.

Mendoza-Roldan, J.A.; Barros-Battesti, D.M.; Bassini-Silva, R.; Jacinavicius, F.C.; NieriBastos, F.A.; Franco, F.L.; Marcili, A. A new species of Pit Mite (Trombidiformes: Harpirhynchidae) from the South American Rattlesnake (Viperidae): Morphological and molecular analysis. Entomology, Ornithology \& Herpetology: Current Research, 6(3), 1-8, 2017.

Moravec, F. Review of capillariid nematodes (Capillariinae) parasitic in amphibians and reptiles. Part 3. Genus Paracapillaria Vestnık Ceskoslovenske Spolecnosti Zoologicke, 50: 273-289, 1986.

Moravec, F.; Santos, C.P. Dracunculus brasiliensis sp. $\mathrm{n}$. (Nematoda: Dracunculidae) from the anaconda, Eunectes murinus (Ophidia: Boidae). Parasitology Research, 104: 589-592, 2009.

O'Dwyer, L.H.; Moço, T.C.; Silva, R.J. Description of the gamonts of a small species of Hepatozoon sp. (Apicomplexa, Hepatozoidae) found in Crotalus durissus terrificus (Serpentes, Viperidae). Parasitology Research, 92(2):110-112, 2003.

O'Dwyer, L.H.; Silva, R.J.; Madeira, N.G. Description of gamontogonic and sporogonic stages of Hepatozoon spp. (Apicomplexa, Hepatozoidae) from Caudisona durissa terrifica (Serpentes, Viperidae). Parasitology Research, 108: 845-851, 2011. 
O'Dwyer, L.H.; Moço, T.C.; Paduan, K.S.; Spenassatto, C.; Silva, R.J.; Ribolla, P.E.M. Description of three new species of Hepatozoon (Apicomplexa, Hepatozoidae) from Rattlesnakes (Crotalus durissus terrificus) based on molecular, morphometric and morphologic characters. Experimental Parasitology, 135: 200-207, 2013.

Paiva, P.; Grego, K.; Lima, V.; Nakamura, A.; Silva, D.; Meireles, M. Clinical, serological, and parasitological analysis of snakes naturally infected with Cryptosporidium serpentis. Veterinary parasitology, 198(1): 54-61, 2013.

Pedraza-Díaz, S.; Ortega-Mora, L.M.; Carrión, B.A.; Navarro, V.; Gómez-Bautista, M. Molecular characterisation of Cryptosporidium isolates from pet reptiles. Veterinary Parasitology, 160: 204-210, 2009.

Pereira, J.; Dias, C.; Filgueira, T.; Freitas, C.; Ahid, S. Infestação por carrapatos em Boa constrictor constrictor (Linnaeus, 1758) de cativeiro, em Mossoró, Rio Grande do Norte. Revista Brasileira de Zoociências, 14(1): 23, 2014.

Pinto, R.; Muniz-Pereira, L.; Panizzutti, M.; Noronha, D. Nematode parasites of the neotropical rattle snake, Crotalus durissus Linnaeus, 1758 (Ophidia, Viperidae) from Brazil: new records and general aspects. Neotropical Helminthology, 4(2): 137-147, 2010.

Pinto, H.; Mati, V.; de Melo, A. New hosts and localities for trematodes of snakes (Reptilia: Squamata) from Minas Gerais State, Southeastern Brazil. Comparative Parasitology, 79(2): 238-246, 2012.

Ramallo, G. Primer registro de Kalicephalus costatus (Nematoda, Diaphanocephalidae), parásito de Liophis miliaris semiaureus (Serpientes, Colubridae) de laprovincia de Entre Ríos. Cuadernos de Herpetologia, 19(1): 53-56, 2005.

Rataj, A.; Lindtner-knific, R.; Vlahovic, K.; Mavri, U.; Dovc, A. Parasites in pet reptiles. Acta Veterinaria Scandinavica, 53 (33): 120, 2011.

Rey, L. Parasitologia-parasitos e doenças parasitarias do homem nos trópicos ocidentais. $4^{\mathrm{a}}$ ed. Rio de Janeiro: Guanabara Koogan, 2008. 883p.
Richter, B.; Kübber-heiss, A.; Weissenböck, H.; Schmidt, P. Detection of Cryptosporidium spp., Entamoeba spp. and Monocercomonas spp. in the gastrointestinal tract of snakes by in-situ hybridization. Journal of Comparative Pathology, 138(2): 63-71, 2008a.

Richter, B.; Kübber-heiss, A.; Weissenböck, H. Diphtheroid colitis in a Boa constrictor infected with amphibian Entamoeba sp. Veterinary Parasitology, 153(1): 164-167, 2008 b.

Ruggiero, P.; Zacariotti, R.; Bondan, E.; Lallo, M. Prevalence of Cryptosporidium serpentis in captive snakes. Ciência Rural, 41(11): 1975 1978, 2011.

Santos, K.; Carlos, B.; Paduan, K.; Kadri, S.; Barrella, T.; Amarante, M.; Da Silva, R. Morphological and molecular characterization of Strongyloides ophidiae (Nematoda, Strongyloididae). Journal of Helmintology, 84(2): 136-142, 2010.

Silva, R.; Barrella, T.H.; Nogueira, M.F.; O'Dwyer, L.H. Frequency of helminths in Crotalus durissus terrificus (Serpentes, Viperidae) in captivity. Revista Brasileira de Parasitologia Veterinária, 10 (2): 91-93, 2001.

Silva, R.J.; Andrade, P.A.; Monteiro e Silva, H.A.; Rossellini, M.; Barrella, T.H. Report on the occurrence of Haplometroides buccicola (Trematoda, Digenea, Plagiorchiidae) infecting Phalotris lativittatus (Serpentes, Colubridae) in Brazil. Journal of Venomous Animals and Toxins including Tropical Diseases, 11(3): 373379, 2005.

Silva, R.; Béda, A.; Ferreira, V. New record of Haplometroides intercaecalis (Digenea, Plagiorchiidae) infecting a Brazilian snake. Journal of Venomous Animals and Toxins including Tropical Diseases, 14(1): 161$165,2008$.

Siqueira, L.; Panizzutti, M. Muniz-pereira, L.; Pinto, R. Descrição de um novo ascarídeo parasito de Bothrops jararaca Wied (Reptilia, Ophidia) no Brasil. Revista Brasileira de Zoologia, 22(3): 587-590, 2005.

Siqueira, L; Panizzutti, M.; Muniz-Pereira, L.; Pinto, R. Gross lesions induced by nematodes of Bothrops jararaca and Bothrops 
alternatus in Brazil with two records. Neotropical Helminthology, 3: 29-33, 2009.

Smith, T.G. The genus Hepatozoon (Apicomplexa: Adeleina). Journal of Parasitology, 82: 565-585, 1996.

Travassos, L. Contribuições para o conhecimento da fauna helminthologica brasileira. XX. Revisão dos Acanthocephalos brasileiros. Parte II. Familia Echinorhynchidae Hamann, 1892, Sub-fam. Centrorhynchinae Travassos, 1919. Memórias do Instituto Oswaldo Cruz, 19(1): 31-125, 1926.

Veazey, R.; Stewart, T.; Snider, T. Ureteritis and nephritis in a Burmese Python (Python molurus bivitattus) due to Strongyloides sp. infection. Journal of Zoo and Wildlife Medicine, 25(1): 119-122, 1994.

Viana, L.; Winck, G.; Almeida-Santos, M.; Telles, F.; Gazeta, G.; Rocha, C. New host records for Amblyomma rotundatum (Acari: Ixodidae) from Grussaí restinga, Rio de Janeiro, Brazil. Revista Brasileira de Parasitologia Veterinária, 21(3): 319-322, 2012.

Zwart, P.; Teunis, S.F.M.; Cornelissen, J.M.M. Monocercomoniasis in reptiles. The Journal of Zoo Animal Medicine, 15 (3): 129-134, 1984. 